\title{
دلالة الجملة الظرفية
}

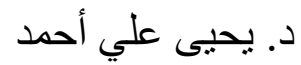

قسم اللغة العربية و آدابها- جامعة الكويت

مدخل

الجملة الظرفية نوع قائم بذاته من الجمل الاسمية، لاشتمالها على ركني الإسناد: المسند إلبه،

و المسند. ويكون المسند إليه (و هو المبتدأ) اسما أو ما هو في حكم الاسم. أما المسند فهو يتكون من: أ) الظرف المضاف، منّ: فوق السطح، عند الباب، خلف السور. أو الظرف المبني: هنالك وثمّ

و غير هما.

ب) الجار ومجروره: في الدار، في البيت...

وقد وردت هذه التسمية لأول مرة عند الزمخثري في معرض حديثه عن أنواع الخبر. فقد عدّ "في الدار" من قوللك (خالد في الدار) "جملة". كما ذكر ابن هشام هذا المصطلح حينما قسم الجملة تقسيما راعى فيه ما يكون في صدر الجملة. فإذا تصدرت الجملة بفعل فهي فعلية. وإذا كان صدر ها ظرفا نحو "أعندك زيد؟ " و "أفي الدار زيد؟ " فهي ظرفية. وسنأتي إلى ذكر ذلك فيما بعد. والذي يمكن أن نخلص إليه هو أن مصطلح "الجملة الظرفية" استعمل في التراث النحوي ليثمل الظرف إلى جانب الجار و المجرور. وقد قيل في بيان سبب هذه التسمية "...إنما سمّي الجار و المجرور ظرفا لأن كثيرا من المجرورات ظرف زمان ومكان، فسمّي الكلّ باسم البعض"(1). و هنالك تعليل آخر ذكره فخر الدين قباوة: "و لأنّ الجار و المجرور غالبا ما يفيدان معنى الظرفية المكانية أو الزمانية فقد توسع النحاة في معنى الظرف، فأطلقوه أحيانا على الجار و المجرور، وجعلوه مر ادفا لثبه الجملة"(2). و هذا تعليل أفضل من سابقه، ويبين أنّ مصطلح الجملة الظرفية في النحو العربي تتضمن صورته 
التركيبية: الظرف أو الجار و المجرور، مثل: أمامك مستقبل مشرق، هناك كتاب، في الدرج أوراق،

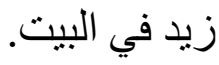
سأتناول في هذه الدراسة هذا النوع من الجمل باعتباره نوعا منميزا من الجمل، نوظفه في واقع الاستعمال اللغوي لنؤدي به معنى الوجود والكينونة. هذا من المنظور الدلالي، أما من المنظور التركيبي فتتميز الجملة الظرفية بأنّ المسند فيها يتألف من مكون ظرفي، بينما هو في الجملة الاسمية اسم. وتعتبر الجملة الظرفية متكاملة، تغني بنفسها، نظر الاستيفائها ركني الإسناد، وهما: المسند و المسند إليه. أما مسار البحث فإنه يبدأ بالنظر في موقف القدماء حول الجملة الاسمية و الجملة الظرفية. ثم ينتقل بعد ذلك لبيان آراء بعض المحدثين الذين تطرقوا إلى طبيعة الإسناد في الجملة الظرفية. وبعد بيان الإطار المرجعي لفكرة الجملة الظرفية، فقد عرضت الرؤية الجديدة التي اقترحتها لتحليل الجملة الظرفية، وهو تحليل يختلف عما قدمه القدماء و اللغويون العرب المعاصرون.

\section{مكونات الجملة العربية}

سيجد الدارس للتفكير اللغوي عند العرب أنّ النحاة الأوائل لم يستعملو ا مصطلح " الجملة " ، ولكنهم - عمليا - ميزوا أنو اعها، وذكروا خصائص كلّ نوع أوحدوده. ولو اتخذنا المنظور التاريخي منطلقا للبحث في هذا الجانب، فلا بدّ أن يكون (الكتاب)، قر آن العربية كما سمي فيما بعد(3)، نقطة البداية. لقد لاحظ العديد من الباحثين العرب المعاصرين و المستشرقين(4) أنّ سيبويه لم يذكر في كتابه مصطلح الجملة، ولكن "تردد في كتابه ذكر مصطلح الكلام كثير ا بمعان مختلفة. فهو يستخدمه بمعنى الحديث، وبمعنى النثر، وبمعنى اللغة، وبمعنى الجملة"(5).

وقد لاحظ أحمد خالد(6) أنّ سييويه إذا أر اد تدقيق مفهوم الجملة، استعمل مصطلحات من قبيل "الكلام المستغني"، و "الاستغناء"، و "كنت مستغنيا"، و "يستغني الكلام". وهذه المصطلحات تدور كلها حول معنى واحد وهو حصول الفائدة لدى المخاطب من الخطاب، ووصول الرسالة اللغوية إليه على 
نحو ما أر اده المتكلم. و على الرغم من عدم استخدام سيبويه لمصطلح الجملة، إلا أنه أسس نهجا اتبعه من جاءوا بعده، فهو الذي أوجد التقسيم الثائع للجمل العربية وهو تقسيمها إلى جملة إسمية وجملة فعلية، وذللك حينما سرد أمثلة نوضيحية للمكوّنين الأساسيين للجملة عنده، وهما المسند والمسند إليه. قال سيبويه في مستهلّ باب المسند و المسند إليه موضحا ما يقصده بهما: "و هما ما لا يَغنى واحد منهما عن الآخر، و لا يجد المتكلم منه بدّا. فمن ذلك الاسم المبتدأ والمبنيّ عليه، وهو قوللك: عبدالله أخوك، و هذا أخوك. ومثل ذلك: يذهب عبدالله. فلا بدّ للفعل من الاسم، كما لم يكن للاسم الأول بدّ من

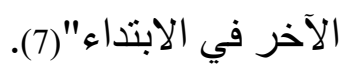
و هكذا فإن أبسط شكل للجملة عند سييويه هو تكونها من ركنين: المسند و المسند إليه. و التركيب الذي يتتكل من هذين الركنين يكوّن بنية إسنادية مفيدة "يستغني به الكلام"، أي يحسن السكوت عليه؛ لأن المعنى يتحقق عندئذ بإسناد أحدها إلى الآخر (8). ويتضح لنا من خلال النماذج التوضيحية أنّ هذين الركنين يفضيان إلى نوعين من الجمل: ـ الجملة الاسمية، وتتكون من المسند إليه (المبتدأ) ، والمسند (وهو الخبر)(9). ـ الجملة الفعلية، وتتكون من المسند (وهو الفعل) ، و المسند إليه (وهو الفاعل). وقد حظي هذا التقسيم الذي أسسه سيبويه باهتمام النحاة، فاتفق جمهورهم على أنّ الجملة الخبرية تتألف في أبسط صور ها من اسمين، أو من فعل واسم. بيد أنّ النحوي الذي قدم تقسيما للجملة شاع في كتب النحو التعليمية قديما وحديثا هو ابن هثام. فقد صنف نوع كلّ جملة بناء على نوع الكلمة المصدرة فيها، كما سنذكر فيما بعد.

\section{مفهوم الجملة الظرفية}

يرتبط تبويب الجملة الظرفية بالجملة الاسمية، إذ يرد تفصيل الكلام عنها في المظانّ النحوية عند عرض الجملة الاسمية وأنواع الخبر. لذا، فإنه يستحسن أن تكون بداية الحديث بأن نذكّر بأنّ الجملة 
الاسمية في أبسط صور ها تتكون من المسند و المسند إليه. وهما يرتبطان ببعضهما من خلال علاقة الإسناد. و هذان الركنان أساسيان في التركيب، لذلك أطلق عليهما النحاة مصطلح "العمد"؛ وهما مما لايغنى واحد منهما عن الآخر، كما عبّر سييويه. ذلك لأن "الكلام لا يكون من جزء و احد، و أنه لا بدّ من مسند ومسند إليه"(10). وبذلك فإنّ المعنى لا يتحقق إلا بإسناد أحدهما إلى الآخر. و المسند إليه هو المبتدأ، "و هو الاسم العاري عن العوامل اللفظية غير الزائدة، مخبر ا عنه، أو وصفا رافعا لمستغنى به"(11). وهو بذللك لا يكون إلا اسما صريحا، أو ما هو بمنزلة الاسم الصريح (المصدر المؤول). أما الخبر (أو المسند) فيتنوع، إذ قد يكون اسما، أو جملة اسمية، أو جملة فعلية، أو شبه جملة (ظرفا، أو

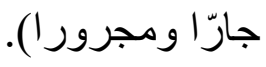
و المبتدأ من المنظور التركيبي هو الكيان الذي نبدأ به عملية الإسناد، أب أنه الاسم المخبر عنه. ومن المنظور الاتصالي هو القضية التي نريد أن نتكلم عنها، إذ إنّ "موضوع الكلام لابدّ أن يرتبط بشيْ ما"(12).. وما نعزوه إلى هذا الكيان يسمى الخبر، و هو الاسم المخبر به. ولذا فإنه من الطبيعي أن برد المبندأ أولا. يقول سيبويه: "فالمبندأ كلّ اسم ابتدئ ليبنى عليه كلام. والمبتدأ و المبنيّ عليه رفع. فالابتداء لا يكون إلا بمبنيّ عليه، فالمبتدأ الأول و المبنيّ ما بعده عليه، فهو مسند ومسند إليه"(13). ويعيد الرضيّ صياغة هذه الفكرة، فيقول في سبب بدء الجملة الاسمية بالمبتدأ: "إنما كان أصل المبتدأ التقديم، لأنته محكوم عليه، و لا بد من وجوده قبل الحكم عليه"(14). إذن فالمبتدأ يرد أو لا من حيث الترتيب. ولما كان المبتدأ هو الثيء الذي نريد أن نتكلم عنه وأن نخبر عنه بشيء ما، لذا فإنه يكون في الأصل معرفة. و هذه هي القاعدة العامّة التي قررها سيبويه، فقد ذكر أن "المعروف"(15) هو ما يجب أن يبدأ به الكلام.. ونجد هذا النمط من التعليل عند ابن السراج (ت 316 هـ) حيث يقول: "إنما امتنع الابتداء بالنكرة المحضة لأنه لا فائدة فيه، وما لا فائدة فيه فلا معنى للتكلم به. ألا ترى أنك لو قلت: رجل قائم، أو: رجل عالم، لم يكن في هذا الكلام فائدة، لأنه لا 
يستنكر أن يكون في الناس رجل قائما أو عالما"(16). وقد نطرّق ابن يعيش (ت 643 هـ) إلى هذا الأمر فذكر في سببه ما يلي: "اعلم أنّ أصل المبتدأ أن يكون معرفة، وأصل الخبر أن يكون نكرة، وذللك لأنّ الغرض في الإخبار ات إفادة المخاطب ما ليس عنده وتنزيله منزلتكا في علم ذلك الخبر. و الإخبار عن النكرة لا فائدة فيه"(17). وينسجم هذان التعليلان مع ما قدمه الاتجاه الوظيفي من أسس ومعايير لتحليل الخطاب اللغوي ضمن سياق الاستعمال الفعلي للغة(18). فآلية الخطاب تبدأ من النية أوالقصد، أب قصد المتكلم بأن يخبر المتلقي عن شيء ما. ووفقا لما يقدره المتكلم أو يعلمه عن مدى إلمام المتلقي بالموضوع، فإنّ المتكلم يبدأ الكلام بما هو معلوم لدى المتلقي، أو يمكن استرجاعه إلى الذاكرة. ويأتي بعد ذلك "الثيء" الجديد الذي يريد المتكلم أن يبلغه إلى المتلقي. وبذلك تتحقق الفائدة من الإخبار. بعد نوضيح تلك النقاط والتي سنعول عليها فيما سيأتي من حديث، نتطرق إلى الخبر حينما يكون ظرفا. وكما بدأنا حديثنا عن مكونات الجملة بالكتاب، فكذلك نبدأ هنا بما ذكره سييويه. تطرق سيبويه إلى الخبر حينما يكون ظرفا، أب شبه جملة، في مكانين مختلفين. وهذا هو أسلوب سييويه، فإنه لا يعالج الموضوع تحت عنوان واحد، خاصة إذا كان الموضوع مسألة نحوية تقتضي معالجات متعددة وفقا لاندماجها أو ارتباطها بتر اكيب و أبو اب أخرى. ولذلك فهو كثير ا ما يتتاول الموضوع الواحد من زو ايا مختلفة، وفي أماكن متفرقة من كتابه.

تحدث سيبويه عن الجملة الظرفية ووظيفتها ضمن تركيب الجملة الاسمية على النحو التالي: "هذا باب ما ينتصب فيه الخبر لأنه خبر لمعروف يرتفع على الابتداء، قدّمته أو أخرته. وذلك قولك: "فيها عبدالله"، و "عبدالله فيها قائما". فعبدالله ارتفع بالابتداء لأنّ الذي ذكرت قبله وبعده ليس به، و إنما هو موضع له، ولكنه يجري مجرى الاسم المبني على ما قبله. ألا ترى أنك لو قلت: "فيها عبدالله" حسن السكوت وكان كلاما مستقيما، كما حسن و استغنى في قولك: "هذا عبدالله". وتقول "عبدالله فيها"، 
فيصير كقولك: "عبدالله أخوك"، إلا أنّ "عبدالله" يرتفع مقدما كان أو مؤخرا بالابتداء. ويدلك على ذلك أنك تقول: " إنّ فيهازيدا"، فيصير بمنزلة قوللك: "إنّ زيدا فيها"، لأنّ "فيها" لما صارت مستقر ا لزيد يستغنى به السكوتُ وقع موقعَ الأسماء، كما أنّ قولك: "عبدالله لقيته" يصير "لقيته" فيه بمنزلة الاسم، كأنك قلت: "عبدالله منطلق". فصار قوللك "فيها" كقوللك "استقرّ عبدالله"، ثم أردت أن تخبر على أية حال استقرّ، فقلت "قائما". فقائم حالٌ مستقرّ فيها" (19). هذا نص طويل، لذا فإنني أريد أن أركز على ما له علاقة بموضوع البحث. 1- المنطلق الذي بدأ منه سيبويه لبيان وضع الجملة الظرفية هو توضيحه لسبب نصب "قائما" في الجملة الظرفية (فيها عبدالله قائما). والتفسير الذي قدمه هو أنّ "المبتدأ" قد عمل فيما بعده عمل الفعل، أي أنه هو العامل الذي نصب "قائما". و [قائما] فضلة، لا شلّّ ، لأن الجملة الظرفية المكونة

$$
\text { المكون الظرفي + الاسم }
$$

عبارة عن جملة تامّة وصحيحة من حيث المبنى و المعنى، أي من حيث التركيب النحوي و التفسير الدلالي؛ وهو (كلام مستقيم)(20)، بدليل أنه يحسن عندها السكوت لأن دلالتها مفهومة، فتقول (فيها عبدالله) بالاستغناء عن الحال. وتكون هذه الجملة جملة تامة مستوفية أركان الإسناد، تماما كما أنّ (21) (هذا عبدالله) جملة تامة.

2- من المعلوم أنّ قواعد النحو التي وضع سيبويه أسسها وتفاصبلها مبنية على نظرية العامل(22). ونجد هنا أنّ سييويه يقررمذهبه في أنّ المبتدأ يرتفع بالابنداء (وهو عامل معنوي)، سواء تقدم: (عبدالله فيها) أم تأخر : (فيها عبدالله). أي أنّ الوظيفة النحوية لا تتغير في هذه الحالة بتغير ترتيب العناصر الإسنادية. ويعضد سييويه هذا التوجه بأن يقدم دليلا لغويا، وهو تغير العلامة الإعرابية للمبندأ في التركيب الإسنادي حينما يدخل عليه عامل لفظيّ مثل ( إنّ ). 
3- يبين سيبويه في هذا النص أنّ "الجملة الظرفية" ليست "خبر ا" بالمعنى المألوف، لأنه لا يتضمن الوصف أو الحكم الذي نريد أن نصف به المبندأ، و هذا مدلول قوله: " لأنّ الذي ذكرت قبله وبعده ليس به". ولكن هذه "الجملة الظرفية" تثير إلى الموقع أو الموضع. وحينما يقول سيبويه عن الظرف الو اقع خبر ا "مستقر ا" ، فإنه يقصد استقر ار الضمير فيه، لأنه يقدر " باستقرّ ". 4- يؤكد سييويه أنّ المكون الظرفي (فيها) ركن أساسي في جملة (عبدالله فيها)، إذ إنه يعادل (أخوك) في جملة (عبدالله أخوك). ففي الحالتين هناك تشكيل يحتل رتبة الخبر، ولكنهما يختلفان من حيث الفئة. ونوضح ذلك فيما يلي: المبتدأ فيها ك كرف عبدالله \أخوك ـ اسم وقد تطرق سييويه للجملة الظرفية في موضع آخر ، حيث اعتبر ها جملة مفيدة في التركيب الإسنادي الذي ترد فيه. و هذا نص كلامه: "هذا باب ما يقع موقع الاسم المبندأ ويسد مسده لأنه مستقرّ لما بعده وموضع. و الذي عمل فيما بعده حتى رفعه هو الذي عمل فيه حين كان قبله؛ ولكن كلّ واحد منهما لا يُستغنى به عن صاحبه، فلما جمعا استغنى عليهما السكوثُ، حتى صار ا في الاستغناء كقولك: "هذا عبدالله". وذلك قوللك: "فيها عبدالله"، ومثله "ثم زيد"، و"هنالك عمرو"، و " أين زيد"، و "كيف عبدالله"، وما أنشبه ذلك(23). بوسعنا أن نتبين في هذا النص جملة أمور أذكر منها ما يتعلق بموضوع البحث: 1- يتحدث سيبويه هنا عن " الجمل الظرفية" حينما يكون المكون الظرفي في مستهل الجملة، على الرغم من أنّ المسند إليه ليس نكرة، وييين أنّ وظيفة هذا الصنف من الجمل تتعلق ببيان " الظرف" 
أو "الككان". ويوضح سيبويه هذه الوظيفة في هذا النصّ من خلال استعمال كلمتين مثر ادفتين، هما "مستقرّ" و "موضع"، وكلتاهما اسم (وصف مشتق)، وليس فعلا. 2- يمكن للجملة الظرفية أن تقع في الموقع الذي يقع فيه المبتدأ (أي يكون أولا)، فيسدّ مسدّه من المنظور التركيبي، لأن الركنين (شبه الجملة + الاسم) أصبحا يشكلان في هذه الحالة جملة تامة مفيدة، تماما كما أنّ جملة (هذا عبدالله) تعتبر جملة كاملة مفيدة. وهو ما عبر عنه سييويه بقوله (فلما جمعا [أي تآلفا بذلك التتابع] استغنى عليهما السكوت). وحينما يستخدم سيبويه عبارة (استغنى عليهما السكوت) فإنه يقصد الجملة المفيدة المستوفية الأركان و التي يحسن السكوت عليها. 3- بعد أن ذكر سييويه أنّ الجملة الظرفية يمكن أن تقع في الموقع الذي يقع فيه المسند إليه، انتقل مبانرة إلى بيان "العامل" الذي سبب رفع المبتدأ (عبدالله). فبين أنّ هذا العامل هو "الابتداء". فكما أن (عبدالله) يكون مرفو عا بالابنداء حينما يكون أولا، فهو يكون مرفوعا أيضا بنفس العامل حينما تتأخر رتبته في نركيب "الجملة الظرفية"، (و الذي عمل فيما بعده [أي بعد الظرف] حتى رفعه [أي رفع المسند إليه]، هو الذي عمل فيه حين كان قبله [أي حين كان المسند إليه في مستهل الجملة] ). 4- يبدأ النص السابق بهذه العبارة "هذا باب ما يقع موقع الاسم المبتدأ ويسد مسده". إن هذا لا يعني أنّ الجملة الظرفية هي "المبتدأ" من الناحية التركيبية، وذلك بقرينة ما ورد بعد ذلك من كلام. وأرى أنّ تفكير سيبويه يتجه في هذه الحالة نحو "ابتداء الكلام". فمن منظور الاتصال اللغوي(24) يبدأ المتحدث - عادة - كلامه بأن يختار عنصر ا مألوفا لدى كل من المتكلم والمستمع، أو ما يعتبر مألوفا لأنه ورد في سياق الكلام. و هذا ما يمثل المعلومة "المعروفة" given ـ وهو يمثل أيضا new موضوع الحديث، أو ما يريد المتكلم أن يبدأ به كلامه. ويعْقب ذللك المعلومة "الجديدة" information المعلوماتية للأمثلة التي أوردها سيبيويه على النحو النالي: 


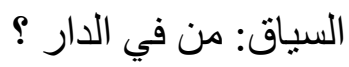

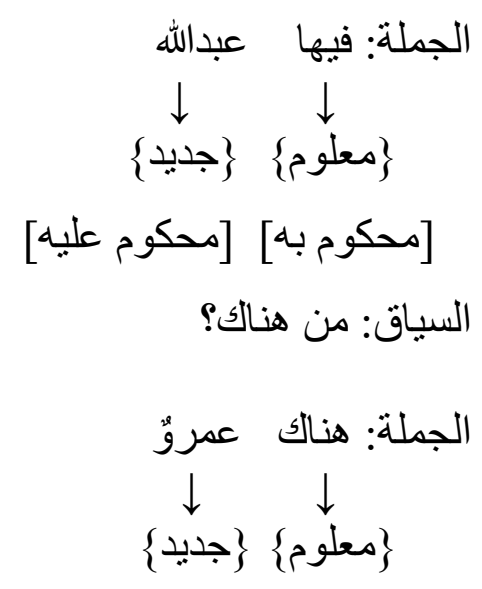

نسنطيع أن نخرج من هذين النصين بخلاصة عامة، وهي أن سييويه قد نعرف على نوع من الجمل الاسمية يحتوي في ركنه الثاني على جار ومجرور أو ظرف، وهو ما سميناه (الجملة الظرفية). وقد أدرك سيبويه بفطنته اللغوية أنّ هذا النوع من الجمل يختلف عن بقية أنواع الجمل الاسمية. وموضع الاختلاف هو أنّ للجملة الظرفية وظيفة دلالية هي بيان الموقع أو المكان. ويتضح من عبار اته (لأنه مستقر لما بعده ... لأنّ "فيها" لما صارت مستقر الزيد يستغني به السكوت وقع موقع الأسماء) أنه كان يقصد الإشارة إلى الوظيفة الدلالية للجملة الظرفية، أما التوجيه الإعرابي الذي يجعل الخبر هو الفعل المقدر المحذوف، فلم يرد ذكره صراحة في النصين السابقين. ولكنّ سييويه تطرق إلى تلك الفكرة بشكل واضح في موضع آخر حيث يقول: "هو خير منك عملا، فصار (هو خلفك)، و(زيد خلفك) بمنزلة ذلك. و العامل في خلف الذي هو موضع له و الذي هو في موضع خبره، كما أنك إذا قلت: "عبدالله أخوك" فالآخر قد رفعه الأول و عمل فيه، وبه استغنى الكلام، وهو منفصل منه"(25). نجد هنا أنّ سيبويه حينما واجه الظرف الذي تظهر عليه علامة النصب (كلمة خلف)، فإنه سارع مباثرة إلى التفكير في العامل الذي نصب ذلك الظرف، وهو في نظره الفعل (استقر). أبي أنّ تقدير الكلام (زيد استقرّ خلفك). ولكن بما أنّ هذا الفعل مقدر ولا يظهر، فقد جعل سييويه ما ناب عنه أي 
(هو) و (زيد) عاملا للظرف. وأصبح الظرف يحتل موضع الخبر. ويورد مثالا تثبيهيا لعمل العامل وهو جملة (عبدالله أخوك). فالعامل في رفع الخبر هو المبتدأ (عبدالله). وعلى الرغم من كون (زيد) في جملة (زيد خلفك) مبتدأ أيضا، إلا أنه لا يمكن اعتباره عاملا تسبب في رفع الخبر، لأن هذا التركيب (زيد خلفك) يختلف عن سابقه (منفصل منه).

وعلى أية حال، فإن التصور الأساسي الذي يمثل موقق سييويه بثأن الجمل الظرفية يمكن تلخيصه في أن تلك الجمل تدل على الموضع أو الموقع. وقد اقتضت فكرة العامل أن يذهب سييويه إلى أنّ ظرف المكان منصوب بفعل مقدر. وإذا لم يكن مثل هذا التقدير واردا، انصرف الظرف عن كونه خبرا. يقول سييويه: "ومن قال (فيها عبدُالله قائم)، قال (هو للك خالص). فيصير [خالص] مبنيا على [ هور ] كما كان [قائم] مبنيا على [عبدالله] ، و "فيها" لغو "26).

ولكن بما أن هذ الفعل المقدر محذوف دائما لأنه لا يظهر ولاينطق (أي أنه موجود في البنية العميقة للجملة فقط)، فإنَّ شبه الجملة يحتل موقع الخبر في البنية السطحية(27).

\section{تطورفكرة أن الجملة الظرفية تتعلق بخبر محذوف}

أخذت هذه الفكرة التي ذكرنا خلاصتها قبل قليل في التوسع شيئا فشيئًا. فمع بروز التوجهات المختلفة في تفسير الظواهر النحوية، وهي ما سميت "الددارس النحوية"، وبدء تغلغل التفسير الدنطقي إلى الدرس النحوي، وكذلك اكتساب نظرية العامل ثقلا في التفكير النحوي، فإنّ تحليل الجملة الظرفية بدأ

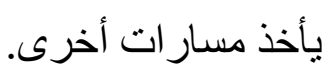
1) قال العكبري (ت 456 هـ) في شرح اللمع: "ويكون خبر المبتدأ ظرفا مكانيا وزمانيا. وحكم الجر ذلك الحكم. تقول: زيد وراءك، و: القتال أمامك، و: الرحيل غدا، و: زيد بالباب، و: الصلح بالبصرة. واعلم أنّ هذا فرع، وأصله أنْ يكون اسم الفاعل خبر المبتدأ، لأنّ الفردد إذا كان خبر المبتدأ، لزم أنْ يكون هو المبتدأ. والوراء والجهة لبستا زيدا، فعلدت أنّ الأصل غير المذكور. والأصل: زيد ثابت، 
أو:مستقرّ، أو:حاصل، وما أشبه ذلك.... وفي اسم الفاعل ضمير ، كما قدمنا ذكره. و الظرف وحرف الجرّ متعلقان باسم الفاعل تعلقهما بالفعل. ثم إنّ العرب حذفت اسم الفاعل اختصار ا، ونقلت الضمير منه إلى الظرف وحرف الجر، فحملا في الضمير، بحق النيابة عن اسم الفاعل، عمل الفاعل في الضمير، فلم ييق لاسم الفاعل علقة بعد حذفه إلا نصب الظرف"(28). إنّ هذا التفسير يركز على الجانب الثكلي المتمثل في التوجيه الإعرابي. ويتضح لنا هذا المسلك حينما يكمل العكبري كلامه ويورد نموذجا إعرابيا يضمنه فكرته عن العامل المدذف: "فإذا قلت: زيد ور اءك، فمعك اسم مرفوع بالابتداء، وضمير مرتفع بأنه فاعل مستكنّ في الظرف، ومسماهما واحد، و هو الراجع من خبر المبندأ إليه، واسم منتصب باسم الفاعل المحذوف، وهو الظرف، وموضع الظرف رفع بأنه خبر المبندأ". والعكبري يتبنى هنا وجهة نظر البصريين في أنّ الظرف في مثل هذه الحالات يتعلق بمدذوف لفظي(29). لاحظ أيضا كيف أنّ العكبري يعرب الظرف أنه في محل رفع خبر المبتدأ.

2) أنشار الزمخشري (ت 538 هـ) في معرض حديثه عن أنواع الخبر إلى أنّ الخبر على نوعين: مفرد وجملة: "...و الجملة على أربعة أضرب: فعلية واسمية وشرطية وظرفية". ووضح ما يقصده بأن أورد هذه الأمنلة: "وذلك: زيد ذهب أخوه، وعمرو أبوه منطلق، وبكر إن تعطه يشكرك، وخالد في الدار"(30). وقد لفت هذا التقسيم انتباه الباحثين قديما وحديثا. فهذا ابن بعيش - شار ح المفصل يعلق على ذلك التقسيم بما يستشفت منه أنه لا يقبل به، ويقول في ذلك: "وهي في الحقيقة ضربان؛ فعلية واسمية، لأنّ الثرطية في التحقيق مركبة من جملتين فعليتين: الثرط فعل وفاعل، و الجز اء فعل وفاعل، و الظرف في الحقيقة للخبر الذي هو استقر ، وهو فعل وفاعل"(31). ويتفق د.ححم حماسة - بعد أن أورد النص السابق - مع رأي الثارح في أنه لايمكن اعتبار الجملة الثرطية نمطا مستقلا بذاته، لأن الثرط معنى من المعاني التي تدخل على الجملة الاسمية. ولكن حماسة لم يتطرق للجملة 
الظرفية(32). أما الدكتور محم عبادة فقد حاول أن يبرر استعمال الزمخشري لمصطلح الجملة وذلك بتفسيره لذلك الاستعمال بأنه مجازيّ راعى فيه الزمخشري ما كانت عليه جملة الخبر قبل وقو عها في ذللك الموقع(33). وقد انتقد د. رابح بومعزة هذا التعليل على أساس أنه يفتقر إلى فهم لوظيفة التركيب في تللك الحالة. وفي رأيه أنّ "الخبرحينما يدخل في تركيب إسناديّ أكبر منه فإنه يصبح غير ذب معنى مستقل بنفسه، وغير غان عن غيره. وبالتالي فلا يمكن معاملته معاملة الجملة المستقلة

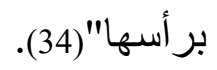

ويبدو لي أن سبب اختلاف المو اقف ووجهات النظر هنا مرجعه إلى توسّع الزمخشري في استعمال مفهوم أنّ الجملة عبارة عن "كلام مستقل بنفسه، مفيد لمعناه ويحسن السكوت عليه(35). إن الحسّ اللغوي المر هف للزمخشري قاده إلى أن يفطن إلى أن أنو اع الخبر تللك تختلف عن الخبر حينما يكون مفردا. ولكن المصطلح الذي استعطله لم يكن معروفا بالمعنى الذي قصده. ولو راجعنا الأمنلة التي استشهد بها الزمخشري، فسنجد أنّ الجمل الثلاث الأول تصنف في التحليل اللغوي المعاصر على أنها clause ، أي جملة صغرى. وأما الجملة الأخيرة فتصنف في النحو التحويلي على أنها "عبارة ظرفية" prepositional phrase في الجملة الاسمية. ولم يعرف العرب مثل هذين المصطلحين. ولنعد بعد هذا الاستطر اد إلى موضوع الجملة الظرفية. لم يسهب الزمخشري منذ البداية في بيان طبيعة الجملة الظرفية، أو مكوناتها التركيبية. وحينما فكر شار ح المفصل في رفض اعتبار الجملة الظرفية نو عا مستقلا من الجمل ، فإنه قدّم لها تفسير ا مختلفا كلّ الاختلاف عن طبيعتها الدلالية. و أما الكتاب المعاصرون الذين علقوا على تقسيم الزمخشري فقد انجرفوا نحو مفهوم "الجملة" بصفتها وحدة لغوية. وضاعت فكرة الجملة الظرفية في هذا النقاش العام. 3) اقترح ابن هشام (ت 761 هـ) في كتابه مغني اللبيب عن كتب الأعاريب تقسيما ثلاثيا للجملة، فقد خصص بابا عنوانه "تقسيم الجملة إلى اسمية وفعلية وظرفية". وقد شرح هذه الأقسام بقوله: 
"فالاسمية هي التي صدر ها اسم، كزيد قائم، و هيهات العقيق، وقائم الزيدان، عند من جوزه وهو الأخفش و الكوفيون. والفعلية هي التي صدرها فعل، كقام زيد، وضُرب اللص، وكان زيد قائما، وظنتنه قائما، ويقوم زيد، وقم. و الظرفية المصدّرة بظرف أو مجرور، نحو: أعندك زيد؟ وأفي الدار زيد؟ إذا قدرت زيدا فاعلا بالظرف والجار و المجرور، لا بالاستقرار المحذوف، ولا مبتدأ مخبرا به عنهما"(36). نجد هنا أنّ ابن هشام قد أضاف إلى جانب القسمين المألوفين: الجملة الاسمية والجملة الفعلية، قسما ثالثا سماه الجملة الظرفية. ولكن يظهر من تحليله لهذا النوع الأخير من الجمل أنّ تسميته تثبر إلى الجانب الثكلي أو الإعرابي. فهو يعتبرها ظرفية لأنها تصدرت بالظرف، وهذا الظرف اعتمد على نفي أو استفهام. و عندئذ يجري الظرف مجرى الفعل فتكون الجملة فعلية، ويكون (زيد) مرفو عا لأنه فاعل. ويفهم من كلامه كذللك أنّ الظرف إذا لم بعتمد على نفي أو استفهام فإنّ الجملة ما تز ال ظرفية ولكنها لا تكون فعلية؛ لذا فإنّ (زيد) سيكون مبتدأ، وليس فاعلا. و لا بد في هذه الحالة من تقدير (استقر) أو أحد مشتقاته، ليكون العنصر الذي يتعلق به الخبر (الظرف). لقد عامل ابن هشام الجملة الظرفية معاملة مستقلة ليس لأنّ تركيبها يفضي إلى دلالة تختلف عن دلالة الجملة الاسمية و الجملة الفعلية، بل كانت معاملته لها منصبة على الجو انب الثنكلية المتعلقة بالتوجيه الإعرابي.

و هكذا نجد أن معالجة الجمل الظرفية بدأت تنحصر شيئا فثيئا في أن الخبر هو في الواقع المتعلق المحذوف، وليس الظرف. وحينما أراد ابن مالك أن يلخص تللك المسألة، فإنه لم يخرج عن هذا الفهح: وأخبروا بظرف أو بحرف جر ناوين معنى "كائن" أو "استقر" وقد قّم ابن عقيل شرحاو اضحا لهذا البيت، لم يخرج فيه عن الإطار التركيبي الذي رسمه ابن مالك لهذا النوع من الجمل، مستبعدا أية اعتبار ات دلالية: "تقدم أن الخبر يكون مفردا، ويكون جملة. وذكر المصنف في هذا البيت أنه يكون ظرفا أو جار ا ومجرورا. نحو: "زيد عندك"، و "زيد في الدار"، 
فكلّ منهما متعلق بمدذوف واجب الحذف. وأجاز قوم - ومنهم المصنف ـ أن يكون ذلك المحذوف اسما أو فعلا، نحو: "كائن"، أو "استقر ". فإن قدرت "كائنا" كان من قبيل الخبر بالدفرد، وإن قدرت "استقر " كان من قبيل الخبر بالجملة"(37).

\section{رأي المحدثين في الجملة الظرفية}

قد يطول بنا البحث لو حاولنا أن نستقصي ما قاله المحدثون حول هذا الموضوع. لذا فسأكتفي هنا بعرض بعض الآر اء.

1) يرى علي مزهر الياسري "أن الجملة الظرفية التي فيها المسند ظرف أو جار ومجرور تام الفائدة في التركيب هي جملة فعلية سواء تقدم أو تأخر، أو اعتد أو لم يعتمد، لأنّ الظرف والجار و المجرور يتضمنان معنى الفعل المضار ع لا بالاستقر ار المحذوف، كما أثنار ابن هشام، وإنما فيهما ذاتهما. ويخرجان إلى الماضي بعارضة لغوية أخرى كدخول (كان) أو غير ها على الكلام"(38). لم يذكر الكاتب لماذا يريد أن يعتبر الجملة الظرفية فعلية، كما أنه لم يورد مثالا تحليليا يتضح من خلاله مدلول الجملة الظرفية وفق ذللك التفسير. وكيف يستقيم أن تدخل "كان" عليها وهي لا تدخل إلا على الجمل الاسمية ؟. و هل المقصود كان الناقصة أم التامة أم الزائدة؟. ولكلّ دلالاتها واستخداماتها ووظيفتها في الجملة سواء من جهة الزمن أم من جهة العمل الإعرابي.

2) خلافا للرأي السابق فان الدكتور علي أبو المكارم يرى أنّ هناك قدرا من التشابه بين الجملة الظرفية و الجملة الاسمية، "يتمثل في أنّ المسند إليه يعرب مبتدأ والمسند خبره. وفي أنّ من الممكن أن يدخل النسخ على هذه الجملة كما تقبله الجملة الاسمية"(39). ومع ذلك فإنّ الكاتب يحترز بأنّ هناك خصائص لغوية تميز مسلك هذه الجملة عن الجملة الاسمية. ويذكر من هذه الخصائص ما يلي(40): 1- أنّ الجملة الظرفية "بسيطة" دائما، و لا تقبل التركيب بحال، في حين أنّ الجملة الاسمية في بعض صور ها بسيطة، وفي بعضها مركبة. كما أنّ من المكن تحويل الجملة البسيطة منها إلى مركبة. 
2- أنّ الجملة الظرفية لاتقبل التطابق بحال، عدديا كان أونوعيا، مباشرا أو غير مباشر، إذ إنّ وظيفة المسند فيها تتحصر في تحديد بعض علاقات المسند إليه، كزمانه أو مكانه. في حين أنّ الجملة الاسمية واجبة التطابق فيها بين عناصر الإسناد. على الرغم من أن الكاتب لايرى أنّ الجملة الظرفية جملة اسمية بل هي تشبهها في بعض الأوجه، إلا أنه يحمد له بأنه نصّ على أنّ لها وظيفة عامة هي الدلالة على الزمان أو المكان. ويتوقف عند ذلك، و لا يذكر في كتابه أية تفاصيل أخرى عن تلك الوظيفة. 3- عرض د. رابح بو معزة في دراسته عن الجملة والوحدة الإسنادية الوظيفية لجوانب تفصيلية تتعلق بالجملة الاسمية و الجملة الفعلية، البسيطة منهما و المركبة، وذلك في إطار طبيعة الإسناد فيهما، ووظيفتهما النحوية. إلا أنه لم يخصص في كتابه قسما للحديث عن الجملة الظرفية. وقد تطرق لذكر الجملة الظرفية بشكل عابر أثناء سرده لتعريف النحويين القدماء للجملة. وهذا هو الأسلوب الذي اتبعه الكاتب في كامل كتابه، فهو يتوقف عند الموضوعات التي أثار ها الباحثون السابقون، ويعرض الآر اءو ويلخصها. وقد توقف عند مسألة اختلف حولها القدماء، وهي هل الظرف هو المعدود خبرا، أم أنه متعلق بخبر محذوف. و إذا كان متعلقا بمحذوف، فهل المحذوف وصف أو فعل؟. وبعد سرد هذه المسألة، فإنه أورد الخلاصة التالية(41): "وسواء أخذنا (كذا) برأي ابن السراج و ابن هشام [اللذين يقدران المحذوف وصفا]، أم برأي سييويه و الزمخشري [اللذين يقدران المحذوف فعلا] ومن يدور في فلكهما فإنّ المركب الظرفي في كلا الحالين لايشكل قسما مستقلا. فالجملة في بنيتها العميقة اسمية أو فعلية. والذي يطمأن إليه هو أن الظرف والجار والمجرور في مثل هذه التراكيب الإسنادية تكون بنيتاهما العميقتان جملة فعلية"(42). و هكذا ينتهي الكاتب إلى الانتصار لأصحاب الر أب من القدماء الذين ذهبو ا إلى أن الخبر الأصلي في الجملة الظرفية فعل محذوف. 
3- يرى المخزومي أنّ الجمل الظرفية، مثل "في البيت رجل"، "عند زيد كتاب"، "أمامك مصباح"... ليست فعلية لأنّ الفعل لا يظهر فيها، وليست اسمية، لأنّ الاسمية هي ما كان المبندأ أو المسند إليه فيها صدر ا، ما لم يطر أ على المسند ما يقتضي تقديمه. وتقدم المسند في هذه الجمل ليس طارئا، ثم إنّ المسند فيها يشير إلى الكينونة العامة أو الوجود العام، مما يجعلها إلى أن تكون فعلية أقرب منها إلى أن تكون اسمية. كل هذا يجعل هذه الجمل بين لا هي اسمية و لا هي فعلية"(43). إنّ الانطباع العام الذي يمكننا أن نخرج به من قراعتنا للكلام السابق هو أنّ الكاتب في حيرة من أمره بخصوص تصنيف الجملة الظرفية. فعلى الرغم من أنه لا يضعها مع الجمل الاسمية ولا الجمل الفعلية، إلا أنه يرى أنها أقرب إلى الجمل الفعلية. والحجة التي لدّح إليها ولم يصرح بها هي أنّ الجملة الظرفية تثير إلى "الكينونة العامة أو الوجود العام"، وهذا يعني أن الجملة الظرفية تحتوي في بنيتها التقديرية على فعل مقدر محذوف. و هذا الر أي هو ما قال به القدماء. وكان حريا بالكاتب أن يكون منسجما مع ما يدعو إليه من نهج جديد في دراسة موضوعات النحو، فيقترح ما ير اه تحليلا جديدا. ذلك أنه انتقد القدماء بقسوة، ووصفهم بأنهم "كانوا يتخبطون في در استهم". وقال: "لابد لنا من أن نصحح نهج القدماء، ونعيد إلى هذه الدراسة [يقصد الدراسة النحوية] اعتبارها الذي جار عليه تعنت النحاة وتمحلهم وجهاهم موضوع در استهم(44). وهذا النقد الثنديد كان بقتضي أن يكون للكاتب تصور مغاير تمام المغايرة لموقف القدماء.

\section{التحليل المقترح للجملة الظرفية}

يتأسس التحليل الذي سأقدمه فيما يلي على فرضية قوامها أنّ الجملة الظرفية جملة تامة مستقلة بنفسها، وتؤدي معنى خاصا لا تؤديه بقية الجمل الاسمية. و هذا المعنى له شقان يرتبط أحدهما بالآخر

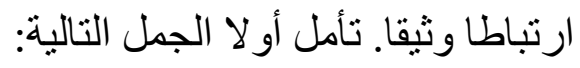




$$
\begin{aligned}
& \text { 1- أ ) زيد هناك } \\
& \text { ب ) هناك زيد } \\
& \text { 2- أ ) في الحديقة أولاد } \\
& \text { ب ) * أو لاد في الحديقة } \\
& \text { (هذه العلامة * تعني أن الجملة غير مقبولة نحويا) } \\
& \text { 3- الكتاب فوق الرف } \\
& \text { 4- هناك أو لاد في الحديقة }
\end{aligned}
$$

في كل جملة من الجمل السابقة نحن نتكلم عن "كيان" أو "شيء" يقع ضمن موضع ما. وهذا هو الثق الأول من المعنى: الدلالة على المكان، أو الكينونة Being. وهذه الدلالة راسخة في الأدوات الظرفية (في، خلف، هنالك، فوق، عندك...). أما الثنق الثاني من المعنى فهو الدلالة على الوجود Existence. و هذه الدلالة مفهومة في إطار التضمسّن implication ـ وبعبارة أخرى فإننا حينما نتكلم عن مكان زيد، فإننا نفهم بداهة أنّ ذلك يتضمن وجود إنسان اسمه زيد في المكان. وهنا نجد كيف أنّ الوجود يرتبط بالكينونة، فنحن حينما نؤكد كينونة (زيد) في الحيز المكاني- الزماني، فنحن كذلك نؤكد وجوده. ويرى كاهْن(45) أنّ هناك علاقة وثيقة بين فكرة "الوجود" و "الموضع" في الفلسفة الإغريقية، إذ إنّ أحدها يتضمن الآخر. وتتأكد هذه العلاقة من خلال المقولة الفلسفية التي شاعت في عصر ما قبل سقر اط: "إذا كان الثيء موجودا فهو موجود في مكان ما، وما لا يوجد في أي مكان فهو لا شيء"(46). ويعقب جون لايونز على هذه العبارة بقوله: "إنّ هذه المقولة الكلاسيكية تتوافق مع وجهات نظرعدد من الفلاسفة التجريبين المعاصرين الذين يذهبون إلى أنّ الجملة الظرفية مرادفة منطقيا للتأثير pointing وبالتأكيد فإنّ الدليل اللغوي يتماشىى مع وجهة النظر هذه"(47). 
و الدليل اللغوي في حالة اللغة العربية هو أنك تستطيع أن تقول: (زيد)، ثم تلجأ إلى فعل غير لغوي و هو أن تؤشّر إلى المكان الذي يوجد فيه زيد. وتقول: (الأولاد)، ثم تؤشر إلى الحديقة. "وتكون وظيفة التأثير هي جذب انتباه المستمع إلى الحيز المكاني- الزماني للثيء"(48). و لا أرغب هنا في أن أخوض في مسألة ميتافيزيقية، وهي: هل الوجود يتضمن الكينونة، أم أنّ الكينونة تتضدن الوجود؟ وبعبارة أخرى، حينما تقول: (زيد هناك)، فهل تريد أن تتكلم عن وجود زيد، أم كينونة زيد في الموضع؟ وبدلا من ذلك، فأنا أتبنّى وجهة النظر التي سبق أن أشرت إليها، وهي أنّ أحدهما يتضمن الآخر. و ألخص وجهة النظر تلك بعبارة أخرى، وهي أننا نتكلم عن وجود ضمنيّ ضمن حبز مكانيزماني معين. و هذا يعني أنّ المتكلم حينما يقول: "زيدٌ في الغرفة"، "على الطاولة كتابٌ"... فإنه يريد أن يقول لنا إنه يعتقد - وقت النطق بالجملة - أنّ شخصا اسمه "زيد"، وشيئا مسماه "الطاولة"، موجود وجودا ماديا في المكان الذي ورد ذكره في كل جملة. وتصدق هذه الدلالة حتى إذا لم يكن

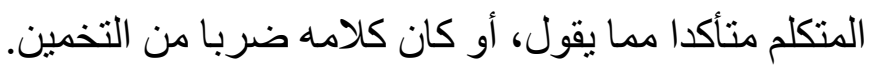

ولنعد الآن إلى الأمثلة (1- 4) التي سبق إيرادها لنلقي عليها بعض الضوء. يُظهر المثالان (1 أ ) و (1 ب ) تبادلا للمو اقع ما بين المبندأ و الخبر. ومن السهل تفسير الجملتين وفقا للبنية المعلوماتية، كما فعل عبدالقاهر الجرجاني(49) حينما حلل الفرق بين هذه الجمل الثلاث: (زيد منطلق)، (زيد المنطلق)، (المنطلق زيد). وهو تحليل ممتاز بكل المقاييس، ويذكرك بلا شك بمفهوم المنظور الوظيفي للجملة functional sentence perspective الذي قدمه أحد أقطاب مدرسة براغ، وهو ماثيسيوس(50) Mathesius يرنكز المنظور الوظيفي للجملة على ثلاثة أركان. الركن الأول يتعلق بالبنية المعلوماتية. إذ إنّ في كل جملة عنصر ا معلوما ربما يشكل الأرضية المشتركة ما بين المتكلم و المستمع، وعنصرا آخر هو المعلومة الجديدة التي يريد المتكلم نقلها. ويتعلق الركن الثاني بالمكونات الإسنادية في الجملة، وكيفية ترتيبها: هل تبدأ الجملة بالمسند ويتلوه المسند إليه، أم يكون 
communicative الترتيب عكس ذلك؟ ولماذا؟ أما الركن الثالث فهو درجات دينامية الاتصال dynamism ويتعلق هذا الأمر بفكرة أنّ عناصر الجملة تسهم في عملية الاتصال بدرجات متفاوتة. فهنالك عناصر تسهم في تطوير الحدث اللغوي وإثراء معلومات المستمع أو القارئ بشكل كبير، و هناك عناصر تسهم في ذلك الأمر بدرجات أقل. فالعنصر الذي يكون له أقل شأن في دينامية الاتصال يبدأ به المتكلم أولا، وهو يقترن غالبا مع المبتدأ (في الجملة الاسمية)، والفعل (في الجملة الفعلية). ويعقب ذلك الأجزاء التي تتضدن المعلومة الجديدة، أي التي تسهم بأكبر قدر في دينامية الاتصال. وتتخذ أجزاء الجملة ترتيبها بناء على سياق الحدث اللغوي، وما يريد المتكلم أن يركز عليه لتقديره أنّ ذلك هو الجديد الذي يتوقعه المستمع. ففي (1 ـ أ ) يكون السياق شيئا من هذا القبيل:

$$
\begin{aligned}
& \text { ـ أين زيد ؟ } \\
& \text { (1- أ ) زيد هناك } \\
& \downarrow \downarrow \\
& \text { > معلوم>> >ديد>> } \\
& \text { أما (1- ب ) فيكون سياقها: } \\
& \text { ـ من هناك ؟ } \\
& \text { (1- ب ) هنالك زيد } \\
& \downarrow \downarrow \downarrow \\
& \text { > معلوم>> > > ل }
\end{aligned}
$$

و هكذا فإن تبادل المو اقع ما بين المبتدأ و الخبر في تللك الجملتين يخضع للبنية المعلوماتية. ولكن من الناحية التركيبية يظل (زيد) مبتدأ سواء تقدم أم تأخر. و السبب في ذلك هو لأنّ الجزء الثني الذي يرتبط به ينتمي لفئة (الظرف)، و هذه الفئة لها تصرف محدود في البنية التركيبية. أما الجملة (2- ب) فإن عدم صحتها يرجع لاعتبار بر اغماتيّ وليس لاعتبار تركيبيّ، وذلك لأنّ الجملة تبدأ عادة بما هو معلوم - أو في حكم المعلوم ـ لدى كلّ من المرسل والمتلقي، وهذا المعلوم 
يقترن مع المبتدا، ثم يأتي بعد ذلك ما يريد المتكلم إبلاغه إلى السامع، وهو الخبر. وهذا النهج الذي ذكرناه بشأن كيفية ترتيب ركني الإسناد ليس شيئا جديدا تمام الجدة جاء به اللغويون المحثثون فقط ، بل هو مفهوم راسخ في الفكر اللغوي العربي. إنّ "نمطية الخطاب الاسمي عند سييويه تتتكل من تعريف عنصر المبندأ، ثم تنكير الخبر"(51). اقرأ مثلا قوله: " و اعلم أنه إذا وقع في هذا الباب نكرة ومعرفة... و إذا قلت (عبدالله منطلق) تبندئ بالأعرف ثم تذكر الخبر"(52). ولهذا تعتبر الجملة (3) صحيحة، بينما الجملة (2- ب) لا تكون كذلك. ونجد عند ابن الأنباري تعليلا لما ذكره سيبويه حيث يقول: "فإن قيل لماذا لا يكون المبتدأ في الأمر العام إلا معرفة؟ قيل: لأن المبتدأ مخبر عنه، والإخبار عما لا يعرف لا فادة منه"(53).

لنتحدث بعد ذلك عن الجملة (4). تتضمن هذه الجملة الظرف (هناك)، وكذلك الجار و المجرور (في الغرفة). فإذا كان كلّ من (هناك) و (في الغرفة) يدلان على الموضع، كما اقترحنا من قبل، فكيف يمكن تفسير الجمع بين الأداتين؟ للإجابة عن هذا السؤال فإنني سأقدم فيما يلي تحليلا مفصلا للظرف (هنالك)؛ وسأبين في هذا التحليل أنه على الرغم من أنّ (هناك) يعتبر ظرفا في كلّ الأحوال من المنظور النحوي، إلا أنه يؤدي عدة وظائف دلالية، وليس وظيفة واحدة كما يدلّ عليها مسماها الإعرابي.

\section{وظائف هناك}

من المعلوم أننا نجد في جميع المظان النحوية، قديمها وحديثها، إجماعا على أنّ (هناك) ظرف للمكان. ويجب أنْ نسلم بأنّ هذا المصطلح يشير إلى الصفة الإعرابية لتلك الكلمة، فالإعراب معنيّ بييان سبب اختلاف النهايات الإعر ابية، وليس بالصفة الدلالية. وحينما نتخذ واقع الاستعمال الفعليّ لهذا الظرف إطار اللتحليل، فإنه يمكننا أن نتعرف على عدة وظائف توضحها الجمل التالية: 
(1) المجموعة (1)

$$
\begin{aligned}
& \text { (1) [أين مكتب البريد؟] ـ هناك مكتب البريد. } \\
& \text { (2) [كان كتابي هنا] } \leftarrow \text { هنالك كتابك. }
\end{aligned}
$$

(3) [صوّر آثار الجريمة] ـ هناك دماء ، (وهنا آثار طلقة نارية).

(2) المجموعة (2)

$$
\text { (1) (1) هناك هناك قطة تحت سيارتي. }
$$

(3) المجموعة

(1) - (1) - مناك مشكلة الفقر في الدول النامية.

(2) هنالك محاو لات لوقف تدهور سعر صرف الدولار.

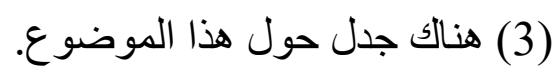

(4) المجموعة

(1) [لأعرف ماذا يمكن أن أقرأه في العطلة الصيفية]

هنالك بخلاء الجاحظ ، روايات نجيب محفوظ ، نو ادر جحا ...

(2) [ماذا يناسب حمينك لوجبة العشاء؟]

هناك الجبنة البيضاء الخالية الدس، فول الصويا، باذنجان بالفرن...

(3) [لخص لنا في أقل من نصف دقيقة المشاكل التي يجب أن توليها الحكومة الجيدة أهمية قصوى]

هناك مشكلة البطلة؛ تردي الخدمات الصحية؛ ارتفاع نسب التضخم ... 
هذه أربع مجموعات، تثتمل كلّ مجموعة على جمل تغطي مجالات استعمال الظرف (هنالك). نستطيع أن نحدد في المجموعة (1) وظيفة (هناك) على أنها أداة في النظام الذي يسميه جون لايونز(54) "النظام الإشاري" deixis system ـ و هذا النظام له مظهر عالميّ، أي أنه لا تخلو لغة من لغات العالم من وجود أدوات فيها أو ضمائر أو أفعال تستخدم للإشارة إلى الثيء. وفي اللغة العربية نستخدم (هنا) للإِشارة إلى القريب، بينما نستخدم (هناك) للإنشارة إلى البعيد. و على الرغم من كون ظرف المكان معرفة بالتأصيل inherently ، إلا أنه، وعلى النقيض من أسماء الإشارة، يعتبر محايدا من حيث الجنس و العدد؛ فلا يؤنث و لا يثنى و لا يجمع. و التصنيف الدلالي يبين لنا أنّ (هنا) و (هناك) ظرف مكان نستخدمه للإشارة إلى المكان؛ والإشارة و الموضع (أو المكان) متلازمان، لأنّ الموضع متضمّن في التأثثير. ولكن يبرز مدلول آخر في هذا الاستعمال، وهو الدلالة على الوجود. و هنا يكون "الوجود" مفترضا presupposed أو مسلما به على أساس الارنباط المنطقي. فحينما نسأل عن شيء أو نتحدث عن موضعه فوجود هذا الثيء مفترض، ونحن نرغب فقط في معرفة مكانه أو موقعه على وجه التحديد. ولهذا السبب فإنّ المبتدأ يكون معرفة شكلا ومعنى، لأنه الثيء الذي يكون معلوما لدى المشاركين في الحدث اللغوي. إذا انتقلنا إلى المجموعة (2) فسنجد أنّ دلالة (هناك) موجّهة لبيان "وجود" شيء ذي خاصية معينة في عالم مادي، ضمن موقع ما. و الدليل على أنّ (هناك) تدل على الوجود في مثل هذه الجمل هو أننا نستعطل معها في نفس السياق الظروف أو حروف الجر التي تعيّن "الككان" على نحو ما يراه المتكلم وقت تفو هل بالجملة. وبعبارة أخرى، يمكننا أن نقول إنّ (هناك) في هذه الاستعمالات أداة وظيفتها لفت النظر إلى وجود شيء يمكن تعيين مكانه، فهي بذللك تمهد للالالة الظرفية، بحيث إننا لو 
وسكتنا، فإن المستمع سر عان ما سيطلب المزيد من المعلومات. سيسألنا ـ مثلا - مباشرة: "أين ؟". فيكون الجواب: في الحمام ، أو : في ذلك الموضع.

وبذا يكون هذا التركيب الظرفي هو الذي أسهم في تعيين مكان الثيء. ويمكن صياغة هذه الحقائق

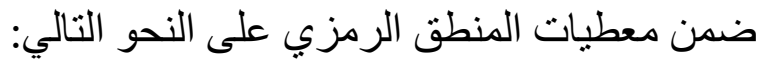

A E x بحيث إن L x 3

حيث لـ عبارة عن فئة عامة universal set ، و A عبارة عن عضو في تلك الفئة set ـ وبعبارة أخرى، فإن تلك الجملة تقول : إن الفئة العامة في هذه الحالة ليست فار غة، لأنها تتضمن A مثالا. بعد هذا الشرح لأمثلة المجمو عتين (1) و (2)، ننتقل إلى المجموعة (3). من الواضح أنّ (هناك) في أمثلة هذه المجموعة لا تؤدي وظيفة بيان المكان، و إنما تدل على "الوجود العام". و هذا الوجود العام لا يرتبط بموضع معين، لذا فإنه يمكن أن نحل بدلا منها كلمة صريحة في الدلالة على الوجود، وهي

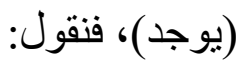

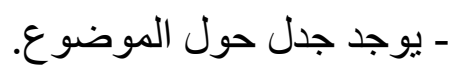
- ت توجد مشكلة الفقر في الدول النامية. و الفرق بين الوجود في المجمو عة (2) و الوجود في المجمو عة (3) أنّ الوجود في المجمو عة (2) هو وجود شيء ماديّ ذي خاصية معينة، بينما الوجود في المجموعة (3) هو وجود عام. لذا، فإنّ الأمثلة في المجموعة (2) قابلة للتكميم quantification ، أي تحديد كمها أو مقدار ها بالاستفسار عن كمية الثيء الوارد ذكره في كلّ مثال، وذلك باستعمال أداة الاستفهام (كم)؛ بينما الأمثلة التي في المجموعة (3) لا تقبل ذلك:

$$
\text { - كم صرصور ا؟ }
$$


(2) هناك مشكلة الفقر في الدول النامية.

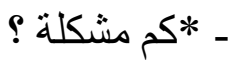

و لا يمكننا أن نتكلم عن وجود ماديّ إلا إذا كان الثيء ينتمي إلى فئة غير فار غة، أي إلى فئة قابلة

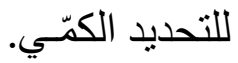
و أخير ا فإننا نلاحظ أنّ المجموعة (4) تقترب في دلالتها من المجموعة (3)، ولكن الفرق أنّ (هناك) في المجموعة (4) تدل على "الوجود المحد"، أي وجود صنف معين أو شيء معين. ويرد هذا الاستعمال حينما يريد المتكلم أن بسرد قائمة من الأشياء الموجودة في ذهنه. وتكون وظيفة (هناك) الدلالة على وجود الأصناف الو اردة مسمياتها في القائمة. و هنا أيضا لا دلالة لـ (هنالك) على الموضع. ويكون النمط التنغيمي لهذا النوع من الجمل مميز الأنها تتضمن سردا لعدد من الأشياء. لذلك فإننا نستعمل النغمة المعلقة عند سرد كل صنف، دلالة على عدم اكتمال الجملة. وتهبط النغمة مع النطق بآخر كلمة إذا كانت القائمة متناهية أو مكتملة. ونوضح هذه الفكرة من خلال بيان الوحدات النغمية للجملة (1) من المجموعة 4 : هناك بخلاء الجاحظ ، روايات نجيب محفوظ ، نو ادر جحا... (قائمة غير مكتملة)

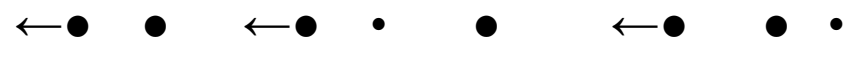

أو:

هناك بخلاء الجاحظ ، روايات نجيب محفوظ ، نو ادر جحا. (قائمة مكتملة)

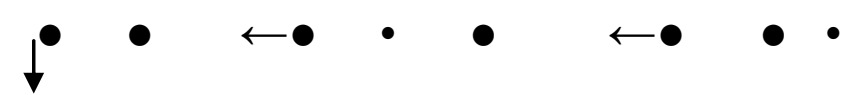

لنعد بعد هذا الثرح إلى الجملة (4). إننا الآن في وضع يسمح لنا بالإجابة عن السؤال الذي سألناه من قبل عن كيف أمكن الجمع بين أداتين تدلان كلتاهما على الموضع، وهما (هناك) و (في الحديقة). إن الظرف (هناك) في الجملة (4) يدلنا على "الوجود"، بينما يدلنا المركب الظرفي الآخر (في الحديقة) 
على الموضع. وهنا نجد أن تآلف ركني الإسناد مع المركب الظرفي بذلك النسق هو ما يرشدنا إلى التفسير الدلالي. ولكنا إذا كتبنا الجملة الظرفية، أو نطقنا بها دون ارتباطها بسياقها، فقد تصبح الجملة

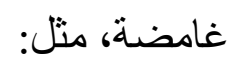

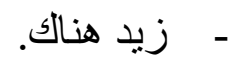

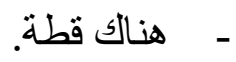

فلا نعلم إذا كان المقصود في كل حالة الإنشارة (الوجود) أو بيان الموضع (الكينونة)، أو ربما مجرد جذب الانتباه إلى الكيان "زيد". و يحرص المتكلم في واقع الاستعمال اللغوي على تجنب الغوض باللجوء إلى بعض الآليات اللغوية الني تحقق له ذللك، منها مثلا: ـ استعمال الفعل "يوجد" حينما يريد تعيين الوجود تحديدا. - وضع نبر الجملة الرئيسي على كلمة (هناك) حينما تكون الإثارة هي الدلالة الرقصودة. أما عندما يكون المقصود جذب الانتباه إلى الكيان، فإننا نضع النبر على كلمة (زيد)، أو قد نقول: - زيد هناك وليس عمرو.

\section{خاتمة وتعقيب}

يتبين من التحليل الذي قدمناه للجملة الظرفية أنها تؤدي وظيفة مستقلة لا تؤديها سائر الجمل الاسمية. و هذه النقطة الأخيرة بحاجة إلى مزيد من الثرح. إنّ الجمل الاسمية التي ينكون ركنا الإسناد فيها من

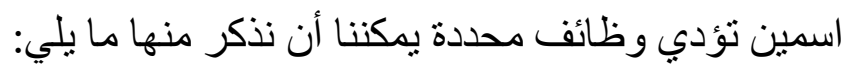
(أ) أن نعزو إلى الدسند إليه وصفا، أو حكما، أو مقولة: 1- البحر هائج. 2- زيد تلميذ. 3- الحكمة ضالة المؤمن. 


$$
\begin{aligned}
& \text { 4- الله وليّ الذين آمنوا. } \\
& \text { (ب) أن نصنف المسند إليه ضمن فئة أو نوع: } \\
& \text { 5- الأسد حيو ان مفترس. } \\
& \text { 6- الإنسان كائن مفكر. } \\
& \text { 7- زيد كهربائي، وأخوه نجار. } \\
& \text { 8ـ المتنبي شاعر. }
\end{aligned}
$$

وفي الحالة الأولى يمكن أن يكون الوصف عرضيا، أي يكون صحيحا وقت النطق بالجملة، أو وقت

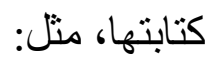

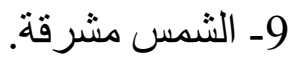

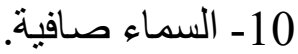

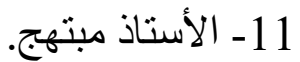

فمثل هذه الأمور ليست ثابتة. وقد يكون الوصف شيئا ثابتا يتصف بالديمومة والتلازم إذا كان يدلّ على حقيقة عامّة،ة، أو يستند إلى معتقد، مثل: 12 - الصيف حار، و الثنتاء بارد. 13- الله غفور رحيم.

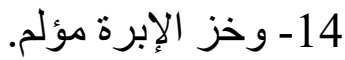

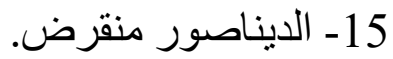
و عندئذ تكون مرجعية كل مقولة ذات دلالة عامة(55). أما في الحالة (ب) فإن إسناد المبتدأ إلى الفئة أو النوع يكون صحيحا إذا كان مطابقا لما هو و اقع. فلو 
16- المتنبي طبيب.

فإن هذه الجملة غير صادقة، لأنه لا يمكن مطابقة التصنيف مع الو اقع. ويستغل مستعملو اللغة حالة عدم مطابقة التصنيف للو اقع لقول الكذب. لنضع النقاط السابقة الذكر نصب أعيننا ونحن نقر أ قول أحد الكتاب المعاصرين وهو يعلق على هذه الجملة (الطفل في المنزل) في سياق ما ظنه نقدا لمسلك القدماء: "هذه جملة اسمية استوفت شروطها عند أهل اللغة، وإعراب مفرداتها على الوجه التالي: الطفل مبتدأ مرفوع وعلامة رفعه الضمة الظاهرة على آخره. في المنزل: جار ومجرور متعلقان بخبر محذوف تقديره (كائن)". ثمّ يكمل الكاتب كلامه ويطرح السؤال التالي: "لماذا لا يكون الجار و المجرور متعقين بخبر محذوف تقديره مسجون مثلا أو حزين أو سعيد في البيت، أو غير ذلك من التأويلات التي تبقى احتمالاتها قائمة مثل

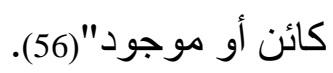

إن اعتر اض الكاتب على موقف القدماء، "و البديل" الذب اقترحه من خلال سؤ اله السابق، يدلّ على عدم فهم لطبيعة الإسناد في الجمل الاسمية، ولما تؤديها الجمل الاسمية من دلالات، تطرقنا لذكر بعضها. ونضيف هنا - إلى جانب ما ذكرناه - قول سييويه: "اعلم أنّ المبتدأ لا بدّ له من أن يكون المبنيّ عليه شيئا هو هو أو يكون في مكان وزمان"(57). يتكلم سييويه هنا، بايجاز دالّ، عن أنّ المسند إليه يرتبط مع المسند بنوع من العلاقة الدلالية. و هو ما لم يتتبه إليه مؤلف ذللك الكتاب. و الردّ على ما ذكره الكاتب أمر يسير. فالكلمات (حزين)، (سعيد)، (مسجون) عبارة عن قيود وصفية. ولو كان مر اد المتكلم أن يعزو إلى المبتدأ مثل هذه الصفات لفعل ذلك مباثرة من خلال العلاقة الإسنادية بين ركني الجملة الاسمية. ولكن الجملة المستشهد بها جملة ظرفية، والجملة الظرفية تتضمن الوجود العام. و الوجود وضع، وليس تصنيفا أو صفة. 
إنّ المنحى الدلالي الذي اتبعناه يقود إلى اعتبار الجملة الظرفية نو عا قائما بذاته من الجمل. وتتفق هذه النتيجة مع ما أنشار إليه ابن مضاء القرطبي عندما اعترض على تقدير متعلقات المجرورات، في تر اكيب مثل (زيد في الدار)، إذ إنه ينكر أن يكون الخبر متعلقا بمحذوف تقديره (مستقر). ويرى أنّ تلاك الجملة عبارة عن كلام تام مركب من اسمين دالين على معنيين بينهما نسبة. وتلالك النسبة دلت

$$
\text { عليها (في)، و لا حاجة إلى تقدير محذوف"(58). }
$$

لاشك أنّ الإطار الفكري الذي كان يخلف هذا الرأي هو رفض نظرية العامل، ولذلك فإنّ ابن مضاء قد صاغ رأيه ليصل إلى هذه النتيجة تحديدا. ولم أكن في هذا البحث معنيا بنظرية العامل، لذا فقد ذهبت إلى أبعد من تلك النتيجة، فبينت الوظيفة الاتصالية للجمل الظرفية، وقدمت لها تحليلا شاملا. وتبقى نقطة أخيرة وهي أن نتساءل عن التوجيه الإعرابي للجمل الظرفية. إنّ التوجيه النحوي الذي أتبناه هو أن نعتبر الجملة الظرفية بأكملها في محلّ رفع خبر،وليس أنها متعلقة بمدذوف خبر. وقد سبق للاكتور محمود نحلة أن انتهى إلى هذه النتيجة. فهو بعد أن سرد مو اقف النحاة، واختلافهم في متعلق الخبر حين يقع جار ا ومجرورا أو ظرفا؛ هل هو فعل أو وصف، فإنه قارن تلك الآراء برأي ابن مضاء السالف ذكره، وخلص بالتالي إلى ما يلي: "و الر أي عندي ما رأى ابن مضاء، وفي القول بعلاقة الإسناد ما يغنينا عن التقدير في هذا وأمثاله"(59). ويمكن تتبع جذور هذا التوجيه الإعرابي إلى بعض الإشار ات الواردة عند النحاة القدماء. من ذلك مثلا ما ذكره العكبري في النص الذي سبق الاستشهاد به، من أنّ "موضع الظرف رفع بأنه خبر المبتدأ. وقول ابن هشام إننا حينما نقول (زيد في الدار)... فإن الضمير [يقصد ضمير الفعل "استقر" المقدر] يكون قد انتقل إلى الظرف بعد أن عمل فيه.(60). صحيح أنّ موقف ابن هثام وتحليله الكامل للجملة الظرفية مبنيّ على أساس نظرية العامل، ولكن يمكن اجتزاء تلك الخلاصة لنقول إنّ الجملة الظرفية في نهاية المطاف هي في محل رفع خبر. ومن جملة المقترحات الأخرى بهذا الثأن 
و الواردة عند القدماء، ما أورده الرضي الاستراباذي(61) في سبب نصب "و اقفا" من قولك (زيد خلفك و اقفا)، إذ روى أنّ عامل النصب هنا هو الظرف لقيامه مقام العامل (وهو الاستقرار المحذوف). فإذا كان يصحّ للظرف أن يكون عاملا، فإنه يصح كذلك أن يحتبر هو ما يمثل الخبر. و أخير ا - وليس آخر ا - نجد أنّ ابن عقيل ينص صر احة على أنّ "ظرف المكان يقع خبرا عن الجثة، نحو: (زيد عندك)، و عن المعنى نحو: (القتال عندك)"(62). وقد تبنى الأستاذ عباس حسن هذا التوجيه الإعرابي المقترح، إذ قال: "فلو قلنا: (ظرف منصوب خبر المبتدأ)، أو: (جار مع مجروره خبر المبتدأ)، من غير أن نزيد شيئا، ما حصل قصور، ولا وقعنا في خطأ، ولكان مساويا في صحته لقولنا: إن شبهي الجملة متعلقان بمحذوف هو الخبر"(63). هذا التوجيه الإعرابي فيه تيسير على متعلمي النحو من غير المتخصصين. ويتسّم كذلك بالبساطة والوضوح لأنه ييين الوظيفة النحوية التي يؤديها المكون الظرفي. و إذا وضعنا هذا التحليل النحوي (أو التركيبي) للجملة الظرفية إلى جانب التحليل الوظيفي الدلالي الذي يبين المعنى المستفاد منها، فإننا نكون قد قدمنا إطار ا تحليليا للجملة الظرفية يعتبر ها نو عا قائما بذاته من الجمل. 


\section{الحواشى و التعليقات}

(1) الأخفش الصنعاني، صلاح بن حسين (ت1142 هـ): نزهة الطرف في الجاروالمجرور

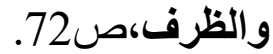

(2) قباوة، فخر الدين: إعراب الجمل وأثباه الجمل، ص 260.

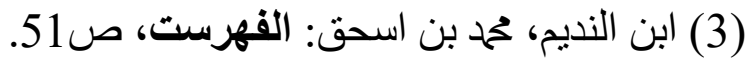

(4) هناك العديد من الدراسات حول موضوع الجملة وتعريفها عند القدماء والمحدثين. انظر على الفى

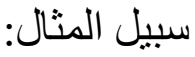

ـ المهيري، عبدالقادر: الجملة في نظر النحاة العرب، حوليات الجامعة التونسية، العدد الثالث

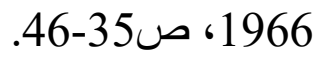
- حاج صالح، عبدالرحمن: "الجملة في كتاب سييويه"، اشغاليات ندوة النحو والصرف ، المجلس الأعلى لر عاية الفنون والآداب و العلوم الاجتماعية، دمشق، ـ عبداللطيف، محم حماسة: بناء الجملة العربية، دار غريب للطباعة النشر، القاهرة 2003. ـ نحلة، محمود أحمد: مدخل إلى دراسة الجملة العربية، دار النهضة العربية، بيروت، لبنان 1988. ـ ـ عبادة، محمد إبراهيم: الجملة العربية، دراسة لفوية نحوية، منشأة المعارف بالإسكندرية، 1988.

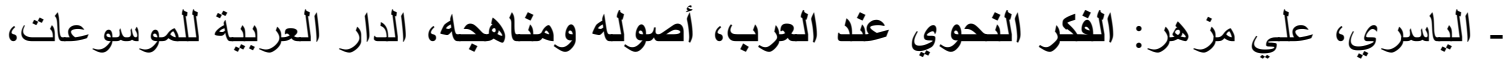
بيروت، لبنان، ـ الثمسان، أبو أوس إبر اهيم: الجملة الثرطية عند النحاة العرب، ط القاهرة 1981.

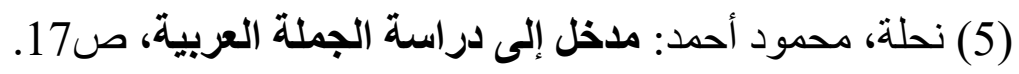

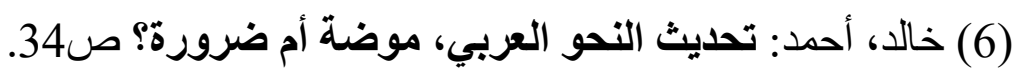

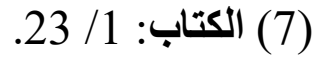

(8) انظر أيضا: بومعزة، رابح: الجملة والوحدة الإسنادية الوظيفية في النحو، تحليل وتصويب

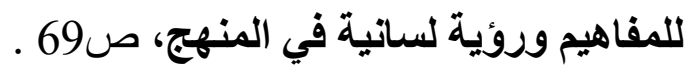
(9) أصل التقسيم الذي اقترحه سيبويه يعدّ المبتدأ هو المسند، والخبر المسند إليه: "فالمبتدأ مسند،

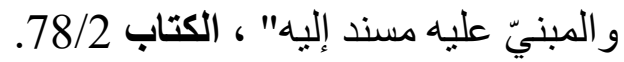

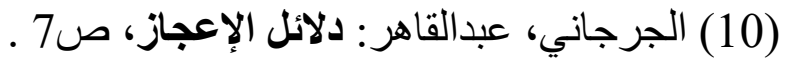
(11) الأشموني، علي نور الدين بن محم بن عيسى: شرح الأثثوني لألفية بن مالك، تحقيق

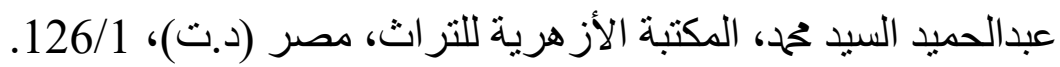


(12) يؤكد هذا الرأي الذي ذكره باحث معاصر هو مانفريد شتذه ما هو مؤصل في التفكير اللغوي العربي حول مفهوم الإسناد. انظر لتفاصيل ذللك الرأي:

Stede, Manfred (2004) Does discourse processing need discourse topic?

Theoretical Linguistics, 30: 241- 253.

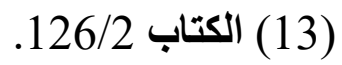

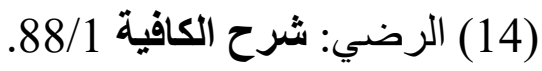

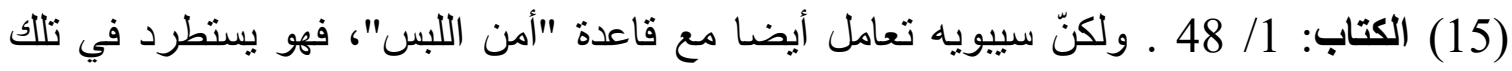
الصفحة وييين أنه يجوز الابتداء بالنكرة في حالات خاصة إذا بات الحققت الإفادة.

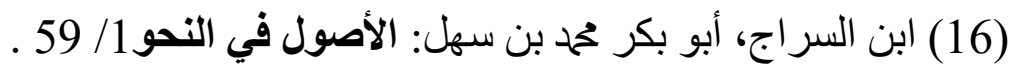

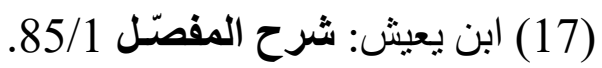

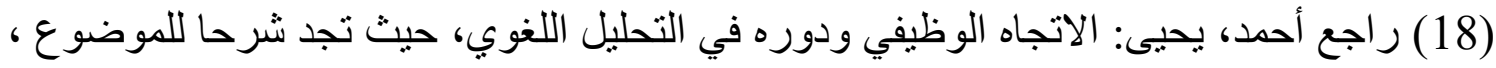

و أمثلة تحليلية.

88/2 (19) الكتاب. (19)

(20) يراجع في ذلك تقسيم سيبويه لمستويات القبول اللغوي للجمل: الكتاب 25/1-26، وهو الأمر الذي عالجه شومسكي في نظريته اللغوية (النحو النحويلي) تحت مسمّى "درجات نحوية الجملة" . degrees of grammaticality

(21) يكرر سييويه هذه الفكرة التي عالجها في تلك الفقرة في موضع آخر، إذ يقول في بيان علة

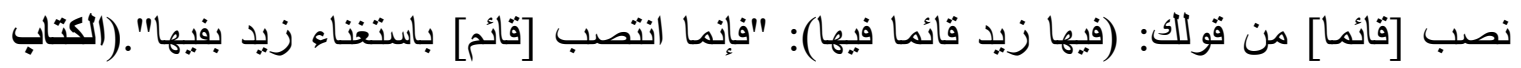
125/2). وذلك لأنّ جملة (فيها زيد) جملة تامة مفيدة.

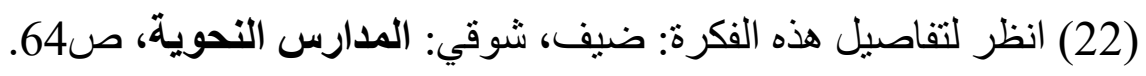

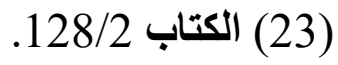

(24) حول مفهوم الابتداء من النظظور النحوي، انظر أقوال النحاة التي جمعتها حصة بنت زيد

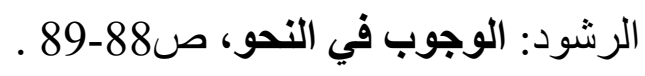

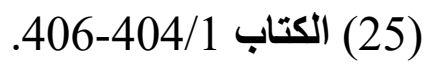

91/2 (26) الكتاب

(27) لو أردنا التيسير في مجال تعليم النحو وقلنا في إعراب (في المنزل، وراءك، خلفك...) إنّ شبه

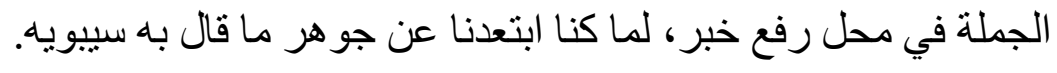




$$
\begin{aligned}
& \text { (28) العكبري، أبو القاسم عبدالواحد ين علي الأسدي: شرح اللمع، / 36-37. } \\
& \text { 216/1) انظر أيضا: شرح الكافية } \\
& \text { (30) الزمخشري: المفصل، ص24. } \\
& \text { (31) ابن يعيش: شرح المفصل 89/1. }
\end{aligned}
$$

(32) عبداللطيف، محمد حماسة: العلامة الإعرابية في الجملة بين القديم والحديث، ص25.

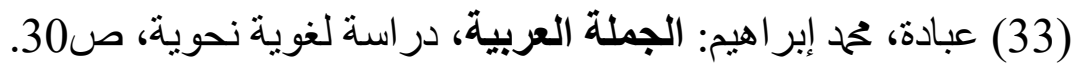

$$
\begin{aligned}
& \text { (34) بومعزة، رابح: الجملة والوحدة الإسنادية، ص20. }
\end{aligned}
$$$$
\text { (35) ير اجع ابن هشام: مغني اللبيب 42/1 ـ . }
$$

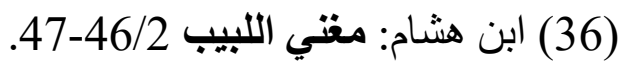$$
\text { (37) ابن عقيل: شرح ابن عقيل ، ص167-168. }
$$

(38) الياسري، علي مزهر محح: الفكر النحوي عند العرب، أصوله ومناهجه، ص314،

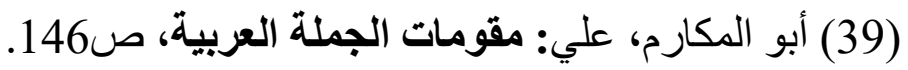

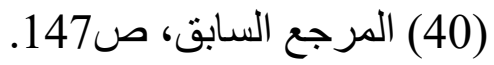

(41) انظر أيضا محمود أحمد نحلة: مدخل إلى دراسة الجملة العربية،وبه، ه5، حيث تجد هذه الخلاصة. ولكن الدكتور بومعزة لا يثير إلى هذا المرجع على الرغم من أنّ تلك الخلاصة مستمدة

(42) بومعزة، رابح: الجملة والوحدة الإسنادية الوظيفية في النحو، ص67.

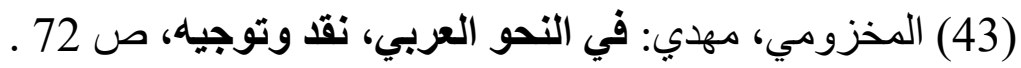

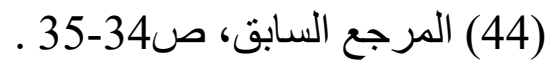

Kahn, Charles H. (1966) The Greek verb "to be" and the concept of (45) being. Foundations of Language, 2: 245-265, p. 258. (46) المرجع السابق، و الصفحة نفسها. نصّ تللك المقولة كالتالي: Whatever is, is somewhere; what is nowhere is nothing Lyons John (1967) A note on possessive, existential and locative (47) sentences. Foundations of Language, 3: 390-396, p. 391. Lyons, John (1977) Semantics, CUP. 654) جون لايونز، الجزء الثاني، صلد8) (49) الجرجاني، عبدالقاهر: دلائل الإعجاز، ص186 ل 
(50) هناك مرجعان جيدان حول المنظور الوظيفي للجملة: أـ باللغة العربية: يحيى أحمد: المرجع الو ارد ذكره في الحاثية (18)

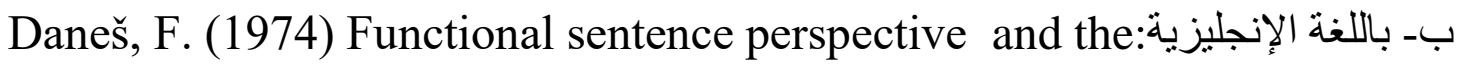
organization of the text. In: František Daneš (ed.) Papers in functional sentence perspective. Mouton: The Hague, pp.106-128

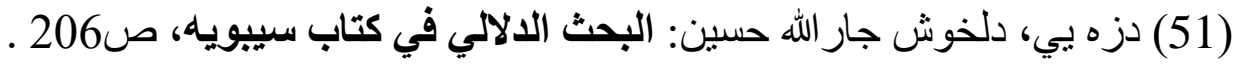

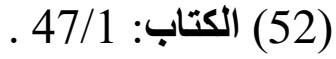

(53) الأنباري، أبو البركات عبدالرحمن به محمد به سعيد: أسرار العربية، ص697.

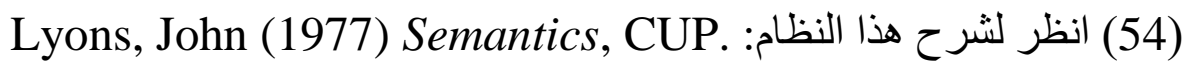
الجزء الثاني، ص647 فما بعد.

(55) يقدم جون لايونز شرحا مستفيضا لمفهوم "المقولة" proposition ـ راجع المرجع السابق

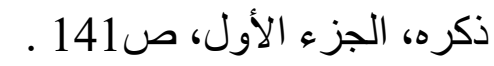
(56) أوزون، زكريا: جناية سيبويه، ص29)

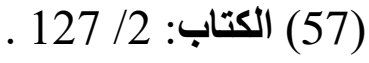

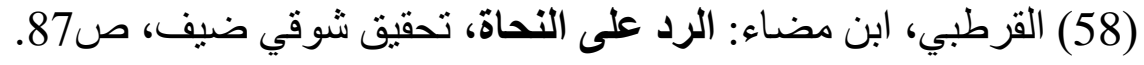

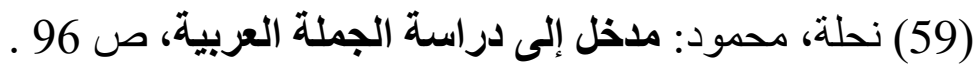

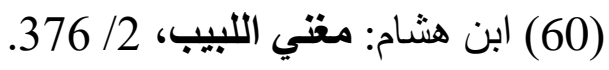
(6161) الاستر اباذي، رضي الدين محمد بن الحسن: شرح كافية ابن الحاجب، /216 216.

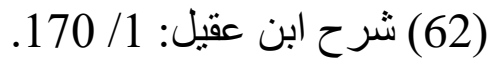

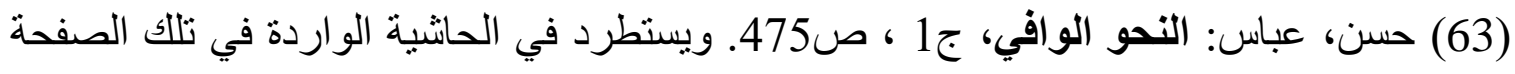

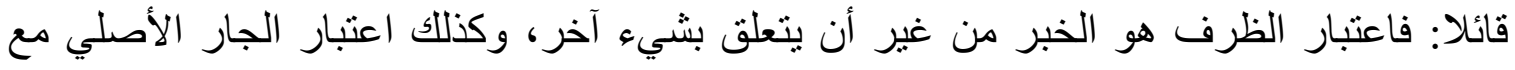

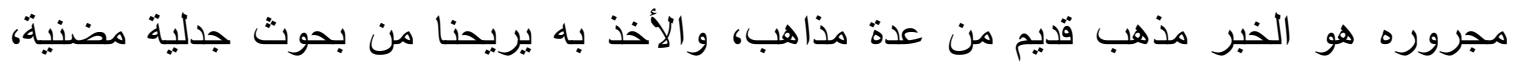
وتقسيمات متعددة، لا نفع لها اليوم، وليس فيها إلا العناء العقلي الذي تضيق بها الناثشئة. 


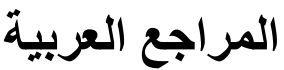

ابن السراج، أبو بكر حمح بن سهل: الأصول في النحو، تحقيق عبدالحسين الفتلي، بيروت، مؤسسة

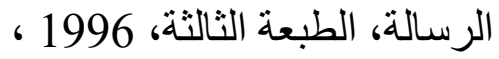

ابن عقيل، بهاء الدين عبدالله بن عقيل العقيلي: شرح ابن عقيل على ألفية ابن مالك،، تحقيق، حنا الفاخوري، دار الجيل، بيروت (د.ت) ابن النديم، محمد بن اسحق: الفهرست، مكتبة الخياط، بيروت، لبنان، د.ت ابن هشام، أبو محمد عبدالله جمال الدين بن يوسف بن أحمد بن عبدالله: مغتي اللبيب عن كتب الأعاريب

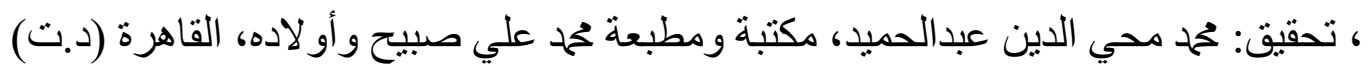
ابن يعيش، موفق الدين بن علي: شرح المفصل ، مكتبة المتنبي، القاهرة (د.ت) أبو المكارم، علي: مقومات الجملة العربية، دار غريب، القاهرة، 2006 أحدة، يحيى: الاتجاه الوظيفي ودوره في التحليل اللغوي، عالم الفكر، 1989 المجلد 56،

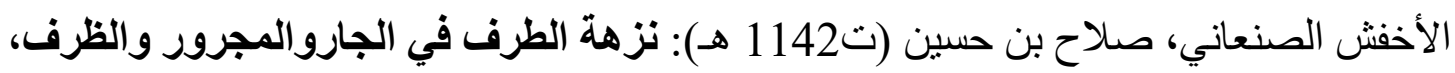
تحقيق، عبدالرحمن بن عبدالقادر المعلمي، دار ابن حزم، بيروت، لبنان، الطبعة الأولى 2005

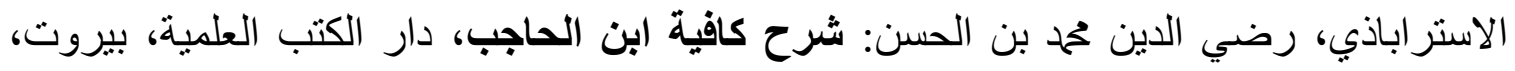
61998 الأشموني، علي نور الدين بن ححمد بن عيسى: شرح الأشموني لألفية بن مالك، تحقيق عبدالحميد

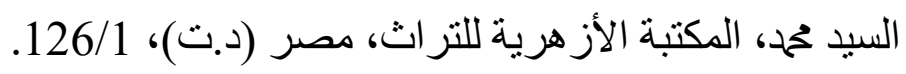
الأنباري، أبو البركات عبدالرحمن به حمحد به سعيد: أسرار العربية، تحقيق محمد بهجة البيطار، مطبعة

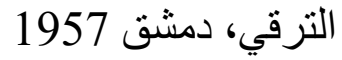
أوزون، زكريا: جناية سيبويه، رياض الريس للكتب و النشر، بيروت، لبنان 2002 بومعزة، رابح: الجملة والوحدة الإسنادية الوظيفية في النحو، تحليل وتصويب للمفاهيم وروئية لسانية في المنهج، دار ومؤسسة رسلان، دمثنق، سوريا 2008 الجرجاني، عبدالقاهر: دلائل الإعجاز، تعليق وتصحيح محمود شاكر، مكتبة الخانجي، القاهرة (ت.د)

حاج صالح، عبدالرحمن: "الجملة في كتاب سييويه"، اشغاليات ندوة النحو والصرف ، الهجلس

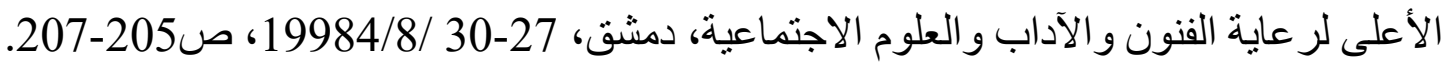

حسن، عباس: النحو الوافي، دار المعارف، القاهرة، 1980. 
حصة بنت زيد الرشود: الوجوب في النحو، جامعة أم القرى، المملكة العربية السعودية، 2000، خالد، أحمد: تحديث النحو العربي، موضة أم ضرورة؛ منشورات Noir sur Blanc ، نونس، 2000

دزه يي، دلخوش جار الله حسين: البحث الدلالي في كتاب سييويه، دار المعتز للنشر و التوزيع، عمان . 2006 الزمخشري، أبو القاسم محمود بن عمر: المفصل في علم العربية، دار الجيل، بيروت: لبنان (د.ت)

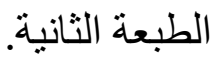
سيبويه، أبو بشر عمرو بن عثمان بن قنبر : الكتاب، تحقيق وشرح عبدالسلام هارون، الطبعة الثالثة، 1988، مكتبة الخانجي، القاهرة. الثمسان، أبو أوس إبر اهيم: الجملة الثرطية عند النحاة العرب، ط القاهرة 1981. ضيف، شوقي: المدارس النحوية، ص64، دار المعارف، الطبعة السادسة 1992. عبادة، محمد إبر اهيم: الجملة العربية، دراسة لغوية نحوية، منشأة المعارف بالإسكندرية، 1988. عبداللطيف، محم حماسة: بناء الجملة العربية، دار غريب للطباعة النشر، القاهرة 2003. عبداللطيف، محمد حماسة: العلامة الإعرابية في الجملة بين القديم والحديث العكبري، أبو القاسم عبدالواحد ين علي الأسدي: شرح اللمع، تحقيق د.فائز فارس، الكويت، 1988، الكئ قباوة، فخر الدين: إعراب الجمل وأشباه الجمل، دار الآفاق الجديدة، بيروت، لبنان، الطبعة الثالثة 1981 القرطبي، ابن مضاء: الرد على النحاة، تحقيق شوقي ضيف، الطبعة الثالثة، دار المعارف بمصر $(ت)$

المخزومي، مهذي: في النحو العربي، نقد وتوجيه، دار الرائد العربي، بيروت، لبنان، 1987،

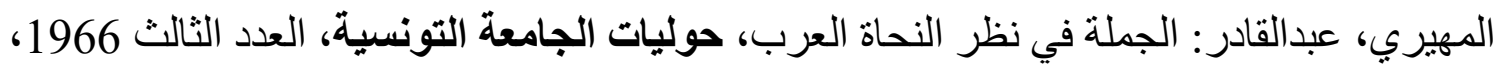

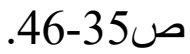

نحلة، محمود أحمد: مدخل إلى دراسة الجملة العربية، دار النهضة العربية، بيروت، لبنان 1988. الرضي، رضي الدين ححمد بن الحسن الاستراباذي: شرح كافية ابن الحاجب، دار الكتب العلمية،

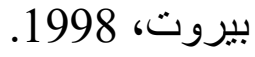
الياسري، علي مزهر تحمد: الفكر النحوي عند العرب، أصوله ومناهجه، الدار العربية للموسوعات،

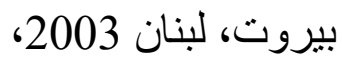




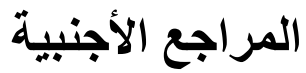

Daneš, F. (1974) Functional sentence perspective and the organization of the text. In: František Daneš (ed.) Papers in functional sentence perspective. Mouton: The Hague, pp.106-128

Kahn, Charles H. (1966) The Greek verb "to be" and the concept of being. Foundations of Language, 2: 245-265

Lyons John (1967) A note on possessive, existential and locative sentences.

Foundations of Language, 3: 390-396

Lyons, John (1977) Semantics, CUP.

Stede, Manfred (2004) Does discourse processing need discourse topic?

Theoretical Linguistics, 30: 241- 253.

\section{دلالة الجملة الظرفية}


تطرق النحاة العرب القدماء للجملة الظرفية، واختلفو ا في تصنيفها لأنهم لم يجدوا في المكون الظرفي علامة ظاهرة تدل على الرفع. لذا، فإنهم لجأوا إلى تقدير وصف مشتق أو فعل يمثل الخبر (المحذوف). ولما اختلف الرأي في العنصر المقدر من كونه اسما أو فعلا، فقد انعكس ذلك على تصنيف الجملة الظرفية إما جملة اسمية، أو فعلية، وفقا للعنصر المقدر. وتدارس الباحثون المعاصرون آراء القدماء، فترددت آراؤهم بين القبول أو إعادة التفسير ضمن الأطر النحوية التي اقترحها القدماء. وينحو هذا البحث منحى مختلفا، فهو يحدد البنى التركيبية للجملة الظرفية، ثم يوجه مسار التحليل نحو الجانب الدلالي- الفلسفي ؛ لأنه هو الجانب الذي يقودنا إلى معرفة الوظيفة المميزة للجمل الظرفية، وهي الدلالة على الكينونة والوجود. أبي بيان الموضع أو المكان صراحة، وبيان الوجود تضمينا. أما التوجيه الإعرابي الذي يأخذ به الباحث، فهو إعراب كامل الجملة الظرفية على أنها في محل رفع خبر، دون تقدير أي شيء محذوف. ويبين الباحث أن هذا التوجيه مستمد من إثنار ات وآر اء وردت عند النحاة القدماء، إلى جانب أنه يتبع مبدأ تيسير تعليم النحو.

\section{The function of locative sentences in Standard Arabic}


Yahia A. Ahmad

Department of Arabic, University of Kuwait.

\section{$\underline{\text { Abstract }}$}

The ancient Arab grammarians recognized locative sentences but their analyses were directed towards what constituted its underlying structure.

Driven by their belief in the existence of an abstract governor i.e. "Eaamil", they suggested that this underlying element could be a noun or a verb. Accordingly, they disagreed upon the classification of locative sentences. The contemporary researchers who studied this topic did not go beyond the theoretical issue of the underlying structure. The present paper adopts a different approach which ends up by analyzing such sentences as denoting location explicitly and existence implicationally. The author argues that analyzing locative sentences within a semantic - philosophical framework will lead us to the proper understanding of these sentences. As for how parsing could be incorporated into this new analysis, the author goes along a line of thought which will in effect get red of a posited underlying element and meanwhile will simplify this chapter of Arabic grammar. 